\title{
A cidadania na Revista Brasileira de Estudos Pedagógicos: publicações entre 1995 e 2013
}

\author{
The citizenship on the Brazilian Magazine of Pedagogical Studies: \\ publications between 1995 and 2013 \\ La ciudadanía en la Revista Brasileña de Estudios Pedagógicos: \\ publicaciones entre 1995 y 2013
}

\section{Maria Augusta Martiarena de Oliveira ${ }^{1}$; Berenice Corsetti ${ }^{2}$}

\section{Resumo}

O tema da cidadania é constantemente utilizado em políticas educacionais e documentos institucionais. O presente trabalho insere-se em uma pesquisa maior, a qual analisa textos publicados na Revista Brasileira de Estudos Pedagógicos entre 1944 e 2013. Este estudo dedicase especificamente ao período compreendido entre 1995 e 2013, fase em que houve maior número de publicações sobre o tema. Objetiva-se compreender a trajetória histórica do conceito de cidadania presente nas publicações da referida revista. Verificou-se que, a partir de 1995, houve aumento substancial no número de publicações sobre o tema. Tais publicações foram marcadas, também, pela variedade de concepções sobre cidadania e sua relação com diferentes áreas do conhecimento.

Palavras-chave: Cidadania. Revista Brasileira de Estudos Pedagógicos. Impressos.

\footnotetext{
${ }^{1}$ Doutora em Educação (História e Filosofia da Educação) pela Universidade Federal de Pelotas, com estágio de pós-doutorado na Universidade do Vale do Rio dos Sinos. Professora do Instituto Federal de Educação, Ciência e Tecnologia do Rio Grande do Sul. E-mail: martiarena.augusta@gmail.com

${ }^{2}$ Doutora em Educação, com estágio de pós-doutorado concluído na Universidade Estadual de Campinas Professora da Universidade do Vale do Rio dos Sinos. Contato: cor7@ terra.com.br
} 


\begin{abstract}
The issue of citizenship is constantly used in educational and institutional policy documents. This paper is a part of a larger study, which analyzes texts published in the Journal of Pedagogical Studies between 1944 and 2013. This study is dedicated specifically to the period between 1995 and 2013, phase in which there was a higher number of publications about the theme. The objective is understanding the historical background of the concept of citizenship present in the magazine publications. We realize, since 1995, there was a substantial increase in the number of publications on the subject. These publications were also marked by the variety of conceptions about citizenship and its relationship with different areas of knowledge.
\end{abstract}

Key words: Citizenship. Brazilian Magazine of Pedagogical Studies. Press.

\title{
Resumen
}

El tema de la ciudadanía es frecuentemente utilizado em políticas educativas y documentos institucionales. Este trabajo es parte de una investigación más ampla, que se propone a analisar textos publicados en la Revista Brasileña de Estudios Pedagógicos entre 1944 y 2013. Este estudio se dedica especificamente al periodo entre 1995 y 2013, momento que más contó com publicaciones sobre el tema. Tenemos por objetivos comprehender la trayectoria histórica del concepto de ciudadanía presente em las publicaciones del referido periódico. Se constató que, a partir de 1995, el número de publicaciones sobre el tema cresció substancialmente. Además, las publicaciones fueron caracterizadas por la variedad de concepciones sobre ciudadanía y su relación com distintas areas del conocimiento.

Palabras-clave: La ciudadanía. Revista Brasileña de Estudios pedagógicos. Impresa. 
A formação cidadã e a cidadania são conceitos frequentemente utilizados em estatutos de instituições educacionais, decorrentes de sua presença na legislação educacional. O título II da LDB, denominado "Dos Princípios e Fins da Educação Nacional”, Art. $2^{\circ}$., afirma que: “A educação, dever da família e do Estado, inspirada nos princípios de liberdade e nos ideais de solidariedade humana, tem por finalidade o pleno desenvolvimento do educando, seu preparo para o exercício da cidadania e sua qualificação para o trabalho". Além disso, o Estatuto da Criança e do Adolescente prevê no Capítulo IV, intitulado "Do Direito à Educação, à Cultura, ao Esporte e ao Lazer", Art. 53. "A criança e o adolescente têm direito à educação, visando ao pleno desenvolvimento de sua pessoa, preparo para o exercício da cidadania e qualificação para o trabalho".

O presente trabalho faz parte de uma pesquisa maior, realizada no âmbito do pósdoutorado em Educação que visa compreender a trajetória histórica do conceito de cidadania, por meio dos discursos educacionais e esse tema, veiculados na Revista Brasileira de Estudos Pedagógicos (RBEP), entre os anos de 1944 e 2013. Destaca-se que a referida revista pode ser considerada uma importante publicação em âmbito nacional, que influencia os debates sobre a educação brasileira.

Para balizar esta pesquisa que utiliza como fonte um impresso pedagógico de circulação com amplo recorte temporal, utilizou-se a periodização proposta por Rothen (2005) para o INEP (Instituto Nacional de Estudos e Pesquisas Educacionais Anísio Teixeira), órgão responsável pela publicação da RBEP:

- Período da influência de Lourenço Filho (1944 a 1951);

- Período da influência de Anísio Teixeira (1952 a 1971), que será subdividido em dois: de 1952 a 1961, que é marcado pelo debate da LDB/61, e o de 1962 a 1971, que é marcado pela discussão da Reforma Universitária e do ensino de $1 .^{\circ}$ e $2 .^{\circ}$ graus;

- Período da busca de identidade, que pode ser subdividido em quatro: o do fortalecimento do INEP como centro de documentação (1972 a 1975); o da tentativa de desmonte do INEP (1976 a 1980); o da aproximação da comunidade acadêmica (1980 a 1995); e o da transformação do INEP em agência de avaliação $\left(1995\right.$ a $2013^{3}$ ).

Faz-se necessário mencionar que o presente estudo propõe uma metodologia de pesquisa baseada na interlocução entre a História Cultural e a metodologia histórico-crítica, pois compreende que embora as referidas correntes ideológicas apresentem posicionamentos diferenciados, o seu diálogo pode perpetrar grandes possibilidades de interpretação e análise. Entende-se que a abordagem pretendida pela História Cultural não se contrapõe à metodologia histórico-crítica, pois baseada no materialismo histórico, pressupõe uma análise dialética da trajetória histórica, com o objetivo de analisar o texto e o contexto. Percebe-se que o elemento cultural se encontra vinculado a um contexto maior e é dele uma representação. Nesse sentido, as práticas culturais (consequentemente educativas) são resultado de um contexto estrutural maior, ao mesmo tempo em que operam para a sua manutenção ou transformação.

O presente trabalho objetiva compreender o conceito de cidadania veiculado na RBEP entre 1995 e 2013. Para tanto, utilizou-se do referido impresso, como fonte de pesquisa.

\footnotetext{
${ }^{3}$ Embora a pesquisa de Rothen (2005) utilize como recorte temporal o ano de 2001, entende-se que não houve alteração no perfil da revista, logo, optou-se por manter a mesma periodização.
} 


\section{Caracterização do impresso utilizado como fonte de pesquisa:}

Atualmente, a importância das investigações embasadas em impressos cresce no âmbito da História da Educação. Conforme Caspard e Caspard (2002, p. 46): “Abundante e diversa, a imprensa pedagógica é um midia muito mais interativo que os tratados ou os manuais e dessa maneira constitui um dos melhores observatórios do movimento social na obra da escola e da formação". Tal afirmação encontra-se em consonância com o que menciona Gonçalves Neto (2002, p.204):

É principalmente através da imprensa que se divulgam e se consolidam as principais representações sociais. E por uma razão muito simples: diferentemente da tradição oral, a palavra escrita pode ser resgatada no futuro e utilizada como documento na construção de interpretações históricas.

Tendo em vista a riqueza de possibilidades de utilização da imprensa pedagógica como fonte de pesquisa, a Revista Brasileira de Estudos Pedagógicos constitue uma possibilidade inestimável de investigação. Destaca-se que existe uma série de investigações que utilizam a Revista Brasileira de Estudos Pedagógicos como fonte e objeto de pesquisa. Primeiramente, ressalta-se que a presente pesquisa se encontra vinculada a uma pesquisa maior, realizada pela Prof. ${ }^{a}$ Dr. ${ }^{a}$ Berenice Corsetti, intitulada "Indicadores de qualidade da educação no Brasil: um estudo a partir da Revista Brasileira de Estudos Pedagógicos (1944 - 2011)”.

Em 1984, ano em que a RBEP completou quarenta anos, foram publicados vários artigos que se dedicavam ao estudo de temáticas no âmbito da própria revista. Entre esses estudos, destacam-se o artigo de Demerval Saviani, de título "A filosofia da educação no Brasil e sua veiculação pela Revista Brasileira de Estudos Pedagógicos"; o artigo de Paulo Rosas, sobre a Psicologia e o estudo de Amélia Domingues Castro, sobre o tema da didática, ambos utilizandose das publicações da RBEP. O Editorial da referida publicação coube a Jader de Medeiros Britto e dedicou-se sobre a presença da Revista na Educação Brasileira.

Além dos estudos anteriormente citados, pode-se mencionar o artigo de Diana Gonçalves Vidal, Marilena Jorge Guedes de Camargo, cujo título é “A imprensa periódica especializada e a pesquisa histórica: estudos sobre o Boletim de Educação Pública e a Revista Brasileira de Estudos Pedagógicos”, publicado em 1992, na própria revista. O artigo dedicavase à análise de duas publicações periódicas, sendo que, com relação à RBEP, as autoras optaram por enfocar o que denominaram movimentos técnico e burocrático. $\mathrm{O}$ primeiro estava ligado diretamente ao programa do Instituto Nacional de Estudos Pedagógicos (INEP). O segundo tratava-se da observação dos fatos educacionais, bem como do exame dos princípios e da análise das questões de aplicação.

Além disso, em 1993, publicou-se o estudo de Valdemar Sguissardi e João dos Reis Silva Jr., intitulado "A produção intelectual sobre educação superior na Revista Brasileira de Estudos Pedagógicos (RBEP): período 1968-1995”, cujo objetivo era, além de estudar a trajetória do tema proposto, relacioná-lo com a história do próprio periódico. Destaca-se, também, o estudo de Lídia Alvarenga, publicado em 2000, denominado "Contribuições para os estudos sobre a pesquisa educacional no Brasil: análise bibliométrica de artigos da Revista 
Brasileira de Estudos Pedagógicos (1944-1974)", o qual se dedicou à análise de 206 artigos da RBEP, publicados entre 1944 e 1974. Bem como a investigação de Inês Ferreira de Souza Bragança, publicado em 2001, cujo título é "Algumas imagens sobre docência e formação na década de 60: revisitando a Revista Brasileira de Estudos Pedagógicos" e objetiva elucidar concepções sobre docência e formação em artigos publicados na década de 1960.

Pode-se mencionar, inclusive, o estudo anteriormente citado, de Rothen, publicado em 2005, o qual serviu de base para a periodização utilizada na presente investigação. O número e variedade de pesquisas realizadas utilizando-se da RBEP demonstram a sua relevância como elemento da imprensa pedagógica e justifica a sua escolha como fonte. Tal periódico destacase tanto pelo tempo de existência, tendo sido criado durante o Estado Novo, pouco tempo depois da criação do INEP e durante a gestão de Lourenço Filho. A pluralidade de áreas que abarca no que tange o âmbito educacional aponta, também, para inúmeras possibilidades de investigações. O presente trabalho, como anteriormente afirmado, optou por analisar os artigos que abordam o tema da cidadania.

\section{A cidadania no final da década de 1990 e a propagação do tema no início do século XXI}

O período abarcado pelo presente estudo refere-se a um período bastante recente e permeado por algumas peculiaridades. Em primeiro lugar, cabe ressaltar que a segunda Lei de Diretrizes e Bases da Educação Nacional foi promulgada em 1996. De acordo com Saviani (2004):

Mas a concepção produtivista de educação resistiu a todos os embates de que foi alvo por parte das tendências críticas ao longo da década de 1980, recobrando um novo vigor no contexto do denominado neoliberalismo, quando veio a ser acionada como um instrumento de ajustamento da educação às demandas do mercado numa economia globalizada centrada na tão decantada sociedade do conhecimento. É essa visão que, suplantando a ênfase na qualidade social da educação que marcou os projetos de LDB na Câmara dos Deputados, se constituiu na referência para o Projeto Darcy Ribeiro que surgiu no Senado e se transformou na nova Lei de Diretrizes e Bases da Educação Nacional, (SAVIANI, 2004, p.50).

Sobre a atualidade, destaca-se o que afirma Oliveira (2011):

ainda que tenhamos alcançado praticamente a universalização do acesso ao ensino fundamental, aumentando seus níveis de conclusão e ampliado o ensino médio para mais de nove milhões de matriculados no início desta década, permanecem grandes e graves problemas de acesso, tendo inclusive a matrícula total desta etapa retrocedido nos últimos anos para aproximadamente 8,3 milhões, sem falar na pequena cobertura da educação infantil, $40 \%$ do grupo etário de 0 a 5 anos, atingindo apenas $20 \%$ na creche, (OLIVEIRA, 2011, p.6). 
Nesse contexto de transformações importantes, ainda que não imediato ao final do período de Ditadura Militar, mas ainda caracterizado pelas profundas marcas deixadas pelas duas décadas de governo autoritário, o tema da cidadania tornou-se uma constante. Como mencionado anteriormente, esse termo encontra-se presente em Projetos Político Pedagógicos, em regimentos e regulamentos institucionais e é amplamente utilizado na legislação educacional. Boneti (2008) considera que a cidadania é utilizada em diferentes situações. Para o autor:

A palavra cidadania está presente nos espaços públicos, nas conversas informais, nos programas e projetos governamentais, etc. de forma que fica um pouco difícil encontrar uma significação uniforme que una todas as situações em que esta palavra é utilizada, (BONETI, 2008, p.23).

O autor ressalta, ainda, que seria possível considerar que a utilização da noção de cidadania está associada, nos dias de hoje, à ideia de coletividade. Para o autor, essa ideia não se restringe ao exercício dos direitos e deveres, mas está relacionada ao que se refere à consciência do entorno.

Entre 1995 e 2013, foram publicados doze artigos na RBEP que abordavam o tema cidadania. Para a seleção nos mesmos, buscou-se, no site do referido periódico, publicações que contassem com o termo cidadania no título, no resumo ou nas palavras-chave. Dos artigos encontrados, dois foram publicados no final da década de 1990 e os restantes, a partir do ano 2000. Destaca-se que, com base na pesquisa de pós-doutoramento, esse trata-se do período com maior número de publicações sobre o tema.

Tabela 1: Publicações que abordam o tema cidadania entre 1944 e 2013.

\begin{tabular}{|l|c|}
\hline \multicolumn{1}{|c|}{ Período } & Número de publicações \\
\hline Influência de Lourenço Filho (1944 - 1951) & 4 \\
\hline Influência de Anísio Teixeira (1952 - 1971) & 0 \\
\hline $\begin{array}{l}\text { Fortalecimento do INEP como centro de documentação (1972 a } \\
\text { 1975) }\end{array}$ & 0 \\
\hline Tentativa de desmonte do INEP (1976 a 1980) & 6 \\
\hline Aproximação da comunidade acadêmica (1980 a 1995) & 12 \\
\hline Transformação do INEP em agência de avaliação (1995 a 2013) & \\
\hline
\end{tabular}

Fonte: Própria autora com base na análise da RBEP 
De acordo com Hilsdorf (2005), as décadas de 1980 e 1990 é costumeiramente denominado como as "décadas perdidas", tendo em vista que não houve melhoria no padrão de distribuição de renda para o todo da sociedade brasileira. A economia caracterizou-se por um relativo crescimento em alguns setores, ao mesmo tempo em que houve um regime inflacionário permanente e "um significativo processo de concentração de rendas, de propriedades, de capital e de marcado", (HILSDORF, 2005, p.127). A década de 1990 e os primeiros anos do século XXI foram marcados pelas políticas neoliberais, as quais delegavam ao setor privado a maior parte de suas obrigações "de maneira tal que os interesses do mercado definem os objetivos, as instituições e os valores da sociedade", (HILSDORF, 2005, p.132). A autora continua:

Para a educação isso significa que o desejo instituinte das camadas populares de ter acesso e sucesso na educação forma está sendo contrariado nos aspectos dos objetivos (formação profissional versus formação crítica ou para a cidadania), da organização institucional (ensino de grupos particulares versus ensino leigo e público) e dos valores (competitividade e individualidade versus cooperação e solidariedade), (HILSDORF, 2005, p.132).

A autora ressalta que as políticas educacionais desse período foram amplamente influenciadas pela agenda privatista de organismos internacionais, tais como o FMI, o Banco Mundial e o BID, os quais apresentam como pontos centrais a privatização e o Estado mínimo.

\section{Cidadania: amplitude de concepções}

Entre 1995 e 2013, 42 \% dos autores são da área da Educação. Sendo que três dedicamse à História da Educação e dois à Filosofia da Educação. O restante dos autores é proveniente de áreas bastante diversas, tais como Arquitetura, Administração, Ciências Naturais, Física, Engenharia, Ciências da Computação, Fotografia, Filosofia e Direito. Percebe-se que a cidadania pode ser considerado um tema relevante para diversas áreas do conhecimento.

Tendo em vista o número de artigos que versam sobre o tema e foram publicados entre 1995 e 2013, optou-se por agrupá-los, levando-se em consideração os temas aos quais se relacionam. Dessa foram, foi possível constituir-se quatro grupos:

1. Cidadania e práticas educativas: Da educação do juízo de gosto e Processo de construção de normas na escola e formação para a cidadania.

2. Cidadania e Ensino Superior: Cidadania docente universitária: a perspectiva dos diplomados; Preparando o futuro: educação, ciência e tecnologia - suas implicações para a formação da cidadania; Desafios de uma rádio universitária diante do compromisso com a educação e a cidadania; Por um olhar democrático às ações afirmativas.

3. Cidadania na perspectiva da História da Educação: As lutas femininas por educação, igualdade e cidadania; A educação nas constituições brasileiras: texto e contexto e A política educacional nacionalista e o aspecto linguístico: vestígios na escola primária.

4. Cidadania, ética e filosofia: Ética como tema transversal e Ensino de Filosofia e cidadania: uma abordagem a partir de Gramsci. 


\section{Cidadania e práticas educativas}

Como acima mencionado, dois artigos relacionam a formação cidadã com determinadas práticas educativas. Em 1998, foi publicado o artigo intitulado "Da educação do juízo de gosto", de autoria de Matheus Gorovitz, o qual discorre sobre a necessidade do ensino das artes e da sua história na educação e afirma que a noção de que a formação do cidadão, do artista e do ser emancipado são interdependentes. Segundo o autor: "Compete ao artista, valendo-se da obra de arte como fator promotor da autoconsciência e autodeterminação (consciência de si), da consciência da cidadania (consciência dos outros), contribuir para a construção da cidade democrática [...]”, (GOROVITZ, 1998, p.89).

Em 2006, foi publicado o artigo "Processo de construção de normas na escola e formação para a cidadania”, de Maria Augusta Salin Gonçalves e Orene Maria Piovesan, o qual se dedica à refletir sobre pesquisa-ação realizada em uma escola de ensino fundamental, com a finalidade de minimizar conflitos existentes na mesma, tendo como foco principalmente o processo de construção de normas, que envolveu alunos, pais, professores, direção e funcionários da escola, e discute os resultados referentes às reuniões realizadas anteriormente com os professores.

O estudo das autoras refere-se a definição de normas por meio de um processo dialógico, o qual envolveu professoras, direção, pais, alunos e funcionários. Ainda que dificuldades e carências tenham sido constatadas, a prática constituiu-se "em momentos significativos que apontam para as possibilidades de formação para a cidadania na escola", (GONÇAVES; PIOVESAN, 2006, p.215). Destaca-se, ainda, que as mesmas afirmam que "colocar limites" é parte integrante dos objetivos de ações educativas que visam contribuir para a formação da cidadania, pois "promovem o exercício da autonomia nas decisões tomadas na perspectiva da responsabilidade social" (GONÇAVES; PIOVESAN, 2006, p.212). De acordo com as autoras:

A escola não pode perder de vista o seu objetivo de incentivar o processo de participação de forma permanente, possibilitando, com freqüência, momentos de discussão, nos quais alunos, funcionários, pais e professoras possam ser realmente críticos, confrontem as suas idéias, reconstruam concepções e decisões e planejem ações coletivas, fazendo do espaço da escola um lugar de formação para a cidadania. Não há dúvidas de que esses momentos são sempre perpassados por conflitos, contradições e rupturas, mas também por vivências de entendimento, (GONÇAVES; PIOVESAN, 2006, p.218).

\section{Cidadania e Ensino Superior}

A maior parte dos artigos publicados no período versam sobre cidadania em contextos de ensino superior. O artigo "Cidadania docente universitária: a perspectiva dos diplomados" foi publicado em 1999, de autoria de Arménio Rego. O referido artigo é oriundo da área da administração e refere-se especificamente ao conceito de cidadania organizacional, cujo significado refere-se aos "comportamentos discricionários, não direta ou explicitamente 
reconhecidos pelo sistema de recompensa formal, e que, no agregado, promovem o funcionamento eficaz da organização", (REGO, 1999, p.405).

Em 2000, foi publicado o artigo de autoria de Alfredo Gontijo de Oliveira, Francisco César de Sá Barreto, Heitor Capuzzo Filho, Ivan Domingues, Paulo Sérgio Lacerda Beirão, Ronaldo Antônio Neves Marques Barbosa e Virgílio A. F. Almeida, intitulado "Preparando o futuro: educação, ciência e tecnologia - suas implicações para a formação da cidadania". O referido artigo dedica-se à análise do papel da educação para a ciência e a tecnologia, em contraste com o papel da ciência e da tecnologia para a educação. Os autores refletem sobre a cidadania na medida em que discutem a questão do que consideram como "humanização da tecnologia".

Também em 2000, foi publicado o artigo "Desafios de uma rádio universitária diante do compromisso com a educação e a cidadania", de autoria de Natercia de Souza Lima Bukowitz. Esse estudo apresenta uma hipótese desenvolvida em visita realizada pelos graduandos em Pedagogia ao estúdio da Rádio da Universidade Católica de Petrópolis. Tais visitas ocorrem no contexto de aulas-passeio, prática concebida por Freinet. Nesse contexto, questionou-se a possibilidade do uso pedagógico da Rádio, que, por meio da inserção dos universitários levaria os ouvintes ao exercício da cidadania. De acordo com a autora: "um trabalho compartilhado com a equipe de comunicadores da Rádio UCP, que subsidiando-nos tecnicamente, estaria incentivando o alcance da autonomia e a prática da cidadania entre os estudantes da instituição", (BUKOWITZ, 2000, p.487).

Em 2011, a RBEP publicou o artigo intitulado "Por um olhar democrático às ações afirmativas", de autoria de Luis Otávio Vincenzi Agostinho e Vladimir Braga Filho, ambos da área do Direito. O objetivo dos autores é discutir as ações afirmativas enquanto forma de que o Estado dispõe para atenuar as desigualdades e os privilégios sociais. O estudo analisa, ainda, as estatísticas que apontam para o fato de que os piores índices de salário, saúde e educação ocorrem com cidadãos negros em comparação aos mesmos índices em relação aos brancos. A compreensão de cidadania neste estudo encontra-se relacionada à alteridade, notadamente no que tange ao comprometimento do cidadão no espaço público e o entendimento de que a cidadania deve ocupar o centro das relações sociais. Além disso, os autores entendem as ações afirmativas como forma de garantir a cidadania e o combate à intolerância.

\section{Cidadania na perspectiva da História da Educação}

O estudo da cidadania na perspectiva da História da Educação esteve presente em três artigos publicados na RBEP. O primeiro, denominado "As lutas femininas por educação, igualdade e cidadania”, de Jane Almeida Soares, foi publicado pela RBEP no ano de 2000. Segundo Soares (2000, p.5): “As mulheres sempre lutaram por direitos que lhes foram negados num mundo construído sob a autoridade masculina". Para a autora, a comprovação dessas lutas se dá pelos vários movimentos feministas, os quais reivindicaram, além do direito político ao voto, educação, instrução, igualdade e cidadania. Dessa forma, o seu estudo dedica-se à apresentar a trajetória desse movimento baseado nas reivindicações femininas. A autora conclui que, mesmo com as conquistas, ainda há muito por fazer nesse sentido.

Em 2007, a RBEP publicou o artigo de Sofia Lerche Vieira, denominado "A educação nas constituições brasileiras: texto e contexto”. O referido artigo se dedica à análise da educação 
nas constituições brasileiras, relacionando-as a elementos do contexto em que foram concebidas. Além disso, o artigo apresenta considerações sobre o conjunto dos textos. A autora aponta para o fato de que os textos das cartas magnas expressam os anseios sociais do contexto em que foram produzidos, sem, no entanto, garantir as reivindicações sociais. De acordo com a autora: "A reflexão sobre esses discursos permite apreciar o contraditório movimento da educação enquanto um valor que passa a incorporar-se aos anseios sociais sem, contudo, oferecer a cidadania plena", (VIEIRA, 2007, p.307).

Em 2009, publicou-se o artigo "A política educacional nacionalista e o aspecto linguístico: vestígios na escola primária”, de autoria de Ademir Valdir dos Santos. O artigo dedica-se a análise de como a educação escolar a serviço do nacionalismo atingiu instituições primárias de regiões de imigração alemã durante o governo Vargas. O autor conclui que: “A escrita revela o uso de textos e imagens como conteúdo estratégico para a inculcação ideológica de valores e atitudes patrióticas na infância".

\section{Cidadania, ética e filosofia}

A relação entre ética e cidadania esteve presente em dois artigos, ambos produzidos pelo mesmo autor, o qual se encontra atuando junto à área da Filosofia da Educação. Em 2009, foi publicado o artigo "Ética como tema transversal", de Renê José Trentin Silveira, o qual analisa e problematiza o tema "Ética", integrante dos Temas Transversais contidos nos Parâmetros Curriculares Nacionais (PCN). Para tanto, o autor analisa o que são temas transversais, a concepção de ética e os pressupostos subjacentes à proposta do tema, bem como as justificativas para que o mesmo integre os temas transversais.

Em 2013, foi publicado o artigo do mesmo autor, denominado "Ensino de Filosofia e cidadania: uma abordagem a partir de Gramsci”. O objetivo desse artigo é discutir a relação entre ensino de Filosofia e preparo para a cidadania. Para tanto, o autor identifica a concepção oficial dessa relação com base na Constituição Federal, na Lei de Diretrizes e Bases da Educação Nacional (LDB) e nos Parâmetros Curriculares Nacionais (PCN) para o Ensino Médio.

\section{Considerações finais}

O termo cidadania, embora já mencionado na década de 1940, é retomado com maior intensidade a partir da década de 1980, ainda sendo considerado um tema controverso. A partir da década de 1990 e com maior intensidade depois de 2000, o tema difunde-se.

Recentemente, os PCNs e as DCN, insistem na estreita relação entre a escola e a formação cidadã. Dessa forma, entende-se que nesse ponto resida um dos motivos para a profusão de pesquisas sobre a temática. Além disso, várias instituições educacionais reiteram a importância da formação cidadã em seus PPI e seus PDI, sejam elas de Educação Básica ou de nível superior. O posicionamento sobre o tema, porém, tende a ser menos crítico do que na década de 1980, período marcado pelo recente fim da ditadura militar. Entretanto, alguns autores como Silveira (2013), alertam para o caráter liberal da concepção de cidadania, presente na legislação nacional, cuja difusão tende mais a manter a ordem estabelecida, do que promover avanços na qualidade de vida das camadas subalternas. 
A partir da década de 1990, no entanto, a formação cidadã retoma a sua importância e o conceito deixa de ser considerado controverso, passando a ser um tema reiteradamente abordado no que se refere à educação. Depois de 2000, vê-se um crescimento do número de artigos dedicados ao tema, a maior parte que compreendem a cidadania como um conceito positivo. Como mencionado anteriormente, o artigo de Silveira (2013), entretanto, apresenta o caráter liberal do conceito no que tange à legislação. Ao analisar artigos e leis, entende-se que, embora a cidadania seja um conceito muito difundido, ainda possui um viés controverso. Além disso, o tema da cidadania encontra-se vinculado aos movimentos sociais, seja no que tange às ações afirmativas, seja na participação feminina na sociedade. A difusão de estudos sobre o tema constitui-se uma forma de propor uma compreensão mais consolidada para o termo.

\section{Referências}

AGOSTINHO, Luís Otávio Vicenzi; BRAGA FILHO, Vladimir. Por um olhar democrático às ações afirmativas. Revista Brasileira de Estudos Pedagógicos, Brasília, n. 232, 2011.

ALMEIDA, Jane Soares. As lutas femininas por educação, igualdade e cidadania. Revista Brasileira de Estudos Pedagógicos, Brasília, n.197, 2000.

BONETI, Lindomar Wessler. Exclusão, Inclusão e Cidadania no ideário neoliberal. In: ALMEIDA, Maria de Lourdes Pinto de; BONETI, Lindomar Wessler (orgs.). Educação e Cidadania no neoliberalismo: da experiência à análise crítica. Campinas, SP: Mercado de Letras, 2008, p.19-34.

BRAGANÇA, Inês Ferreira de Souza. Algumas imagens sobre docência e formação na década de 60: revisitando a Revista Brasileira de Estudos Pedagógicos. Revista Brasileira de Estudos Pedagógicos, Brasília, v. 82, n. 200/201/202, p.7-14, jan/dez 2001.

BRASIL. Lei Federal $n^{\circ}$ 8.069, de 13 de julho de 1990. Institui o Estatuto da Criança e do Adolescente. Disponível em <http://www.planalto.gov.br/ccivil_03/Leis/L8069.htm>. Acesso em 10 ago. 2013.

BRASIL. Lei Federal no 9. 394, de 20 de dezembro de 1996. Estabelece as Diretrizes e Bases da Educação Nacional. Disponível em <http://portal.mec.gov.br/arquivos/pdf/ldb.pdf > . Acesso em: 10 ago. 2013.

BRITTO, Jader de Medeiros. Editorial: Presença da Revista na Educação Brasileira. Revista Brasileira de Estudos Pedagógicos, Brasília, v. 65, n. 150, p. 239-240, maio/ago. 1984.

BUKOWITZ, Natercia de Souza Lima. Desafios de uma rádio universitária diante do compromisso com a educação e a cidadania. Revista Brasileira de Estudos Pedagógicos, Brasília, n.199, 2000.

BURKE, Peter. A Escola dos Annales (1929 - 1989): a revolução francesa da historiografia. 2.ed. - São Paulo: Editora da UNESP, 2010.

BURKE, Peter. O que é História Cultural? 2.ed. rev. e ampl. Rio de Janeiro: Jorge Zahar Ed, 2008. 
CASPARD, Pierre; CASPARD, Pénélope. A imprensa pedagógica e formação contínua dos professores (1815 -1939). In: CATANI, Denice; BASTOS, Maria Helena (orgs.). Educação em Revista: a Imprensa Periódica e a História da Educação. $1^{\text {a }}$ Reimpressão. São Paulo: Escrituras Editoras, 2002.

GONÇALVES, Maria Augusta Salim; PIOVESAN, Orene Maria. Processo de construção de normas na escola e formação para a cidadania. Revista Brasileira de Estudos Pedagógicos, Brasília, n.216, 2006.

GONÇALVES NETO, Wenceslau. Imprensa, civilização e educação: Uberabinha (MG) no início do século XX. In: ARAÚJO, J. C. S.; GATTI JR., D. (Orgs.). Novos temas em história da educação brasileira. Instituições escolares e educação na imprensa. Campinas, SP: Autores Associados; Uberlândia, MG: EDUFU, 2002, p.197-225.

GOROVITZ, Matheus. Da educação do juízo de gosto. Revista Brasileira de Estudos Pedagógicos, Brasília, n.196, 1998.

HILSDORF, Maria Lucia Spedo. História da Educação Brasileira: Leituras. São Paulo: Pioneira Thomson Learning, 2005.

NÓVOA, António. A Imprensa de Educação e Ensino: concepção e organização do repertório português. In: CATANI, Denice Bárbara; BASTOS, Maria Helena Câmara. Educação em Revista: A Imprensa Periódica e a História da Educação. - São Paulo: Escrituras Editora, 2002, p.11 a 32 .

OLIVEIRA, Alfredo Gontijo de; BARRETO, Francisco César de Sá; CAPUZZO FILHO, Heitor; DOMINGUES, Ivan; BEIRÃO, Paulo Sérgio Lacerda; BARBOSA, Ronaldo Antônio Neves Marques; ALMEIDA, Virgílio A. F. Preparando o futuro: educação, ciência e tecnologia - suas implicações para a formação da cidadania. Revista Brasileira de Estudos Pedagógicos, Brasília, n.198, 2000.

REGO, Aménio. Cidadania docente universitária: a perspectiva dos diplomados. Revista Brasileira de Estudos Pedagógicos, Brasília, n.196, 1999.

ROTHEN, José Carlos. O Instituto Nacional de Estudos Pedagógicos: uma leitura da RBEP. Revista Brasileira de Estudos Pedagógicos, Brasília, v.86, n. 212, p. 189-224, jan/abr 2005.

SAAVEDRA, Silvia Maria Galiac. Passos e descompassos de uma instituição de pesquisa educacional no Brasil: a realidade do Inep. Brasília, 1988. 279 f. Dissertação (Mestrado em Educação) - Universidade de Brasília.

SANTOS, Ademir Valdir dos. A política educacional nacionalista e o aspecto linguístico: vestígios na escola primária. Revista Brasileira de Estudos Pedagógicos, Brasília, n. 225, 2009.

SAVIANI, Demerval. História das ideias pedagógicas no Brasil. - 2. Ed. Rev. e ampl. Campinas, SP: Autores Associados, 2008.

SAVIANI, Demerval. A filosofia da educação no Brasil e sua veiculação pela Revista Brasileira de Estudos Pedagógicos. Revista Brasileira de Estudos Pedagógicos, Brasília, n. 150, p. 273 290, jun./ago. 1984. 
SGUISSARDI, Valdemar; SILVA JR., João dos Reis. A produção intelectual sobre educação superior na Revista Brasileira de Estudos Pedagógicos (RBEP): período 1968-1995. Revista Brasileira de Estudos Pedagógicos, Brasília, v.79, n; 193, p. 95-112, set/dez 1998.

SILVEIRA, Renê José Trentin. Ética como tema transversal. Revista Brasileira de Estudos Pedagógicos, Brasília, n. 226, 2009.

Ensino de Filosofia e cidadania: uma abordagem a partir de Gramsci. Revista Brasileira de Estudos Pedagógicos, Brasília, n. 236, 2013.

VIEIRA, Sofia Lerche. A educação nas constituições brasileiras: texto e contexto. Revista Brasileira de Estudos Pedagógicos, Brasília, n. 219, 2007. 